\title{
Panorama teórico da Fonologia no Brasil: uma homenagem a Leda Bisol
}

\author{
Camila Witt ULRICH (®) \\ Universidade Federal do Rio Grande do Sul (UFRGS) \\ Raquel Gomes CHAVES (1) \\ Universidade Federal de Pelotas (UFPEL)
}

○

OPEN ACCESS

EDITADO POR

Raquel Freitag

AVALIADO POR

Carmen Matzenauer

SOBRE OS AUTORES

Camila Witt Ulrich

Contribuiu com Raquel Gomes

Chaves. Papéis: visualização, escrita - rascunho original.

Raquel Gomes Chaves Contribuiu com Camila Witt Ulrich. Papéis: visualização, escrita - rascunho original.

DATAS

Recebido: 05/08/2020

Aceito: 04/09/2020

Publicado: 09/09/2020

COMO CITAR

Ulrich, C. W.; Chaves, R. G. (2020). Panorama teórico da Fonologia no Brasil: uma homenagem a Leda Bisol. Revista da Abralin, v. 19, n. 2, p. 1-6, 2020.
RESUMO

A mesa redonda Fonologia, conduzida por José Magalhães (UFU) e organizada em homenagem à professora Leda Bisol, apresenta um panorama dos estudos em Fonologia a partir de diferentes perspectivas teóricas. Carmen Matzenauer (UFPEL) aborda a Fonologia Gerativa Clássica, pautada nos conceitos de níveis de representação, regras e traços, e nos desdobramentos do modelo teórico. Luciani Tenani (UNESP - São José do Rio Preto) introduz os pressupostos da Fonologia Prosódica - teoria que organiza o contínuo da fala em constituintes prosódicos hierarquizados. Christina Abreu Gomes (UFRJ) trata da Fonologia baseada no Uso e no Modelo de Exemplares, que prevê abstrações emergentes do uso e da experiência linguística dos falantes.

\section{ABSTRACT}

The roundtable Phonology, moderated by José Magalhães (UFU) and organized in honor of Professor Leda Bisol, presents an overview of studies on Phonology from different theoretical perspectives. Carmen Matzenauer (UFPEL) introduces Classical Generative Phonology, based on concepts such as levels of representation, rules and features, and its subsequent developments. Luciani Tenani (UNESP - São José do Rio Preto) presents the premises of Prosodic Phonology - a theory that organizes the speech continuum into hierarchical prosodic constituents. Christina Abreu Gomes (UFRJ) deals with Usage-based Phonology and the Exemplar Model, which 


\section{REVISTA DA ABRALIN}

predicts emerging abstractions from the use and linguistic experience of speakers.

\section{PALAVRAS-CHAVE}

Fonologia Gerativa Clássica. Fonologia Prosódica. Modelo de Exemplares.

\section{KEYWORDS}

Classical Generative Phonology. Prosodic Phonology. Exemplar Model.

Parte do evento virtual Abralin ao vivo - Linguists online, esta resenha trata da mesa redonda Fonologia, ocorrida em 29 de julho de 2020 sob mediação do Prof. José Magalhães (UFU). A mesa, em homenagem à Profa. Leda Bisol (UFRGS), abordou diferentes perspectivas dos estudos fonológicos e contou com a participação das professoras Carmen Matzenauer (UFPEL), Luciani Tenani (UNESP São José do Rio Preto) e Christina Abreu Gomes (UFRJ).

Fonologia no Brasil tem nome e sobrenome: Leda Bisol. Assim iniciou a belíssima homenagem feita à professora em virtude do imenso trabalho desenvolvido por ela no que se refere à fonologia do português. Leda, além de ter orientado expoentes da fonologia brasileira, desenvolveu trabalhos sobre inúmeros temas, os quais estão inseridos em diversos modelos teóricos ${ }^{1}$, fato que atesta sua versatilidade como pesquisadora. Dentre outras iniciativas encabeçadas pela professora, destaca-se seu papel fundamental na constituição do Projeto VARSUL ${ }^{2}$. Além disso, Leda é pesquisadora Nível 1A/CNPq e recentemente recebeu o título de Professora Emérita pela Universidade Federal do Rio Grande do Sul (UFRGS).

O moderador abre a mesa apresentando o percurso histórico dos estudos em fonologia, campo do conhecimento que se firma como disciplina concomitantemente ao estabelecimento da linguística como ciência. Magalhães apresenta um panorama dos estudos fonológicos: seu percurso inicia no estruturalismo, passa pelos inúmeros modelos gerativos, dentre os quais destaca Fonologia Clássica (CHOMSKY; HALLE, 1968), Fonologia Lexical (KIPARSKY; 1982), Fonologia Métrica (LIBERMAN; PRINCE, 1977), Fonologia Prosódica (NESPOR; VOGEL, 1986), Teoria da Otimidade (PRINCE, SMOLENSKY, 1993) e, por fim, Fonologia de Uso (BYBEE, 2001). A ordem dos temas abordados por cada uma das conferencistas segue a cronologia das vertentes teóricas previamente apresentadas pelo moderador.

\footnotetext{
1 Entre os principais temas estudados por Leda Bisol, podemos citar vogais, sílabas, acento, ditongo, nasalidade, constituência prosódica e variação fonológica. Esses temas estão inseridos em diferentes modelagens, a saber, estruturalismo, gerativismo clássico, fonologias não lineares - Fonologia Lexical, Modelos Métricos, Teoria da Otimidade - e também Fonologia de Uso.

2 O Projeto VARSUL é um banco de dados constituído de amostras de fala de habitantes de 12 cidades da Região Sul do Brasil. Mais informações sobre o projeto podem ser encontradas em http://www.varsul.org.br/. Acesso em 4 de ago. de 2020.
} 


\section{REVISTA DA ABRALIN}

A exposição inicia com a apresentação de Carmen Matzenauer (UFPEL), que trata da Fonologia Gerativa Clássica e dos modelos gerativos subsequentes. Em sua fala, Carmen aponta a fonologia gerativa como um marco no desenvolvimento dos estudos sobre o componente fonológico, enfatizando dois aspectos: i) conceitos fundamentais sobre níveis de representação, regras e traços, e ii) desdobramentos a partir da Fonologia Gerativa Clássica (com foco na Fonologia Autossegmental).

A fonologia gerativa visa à construção de uma gramática fonológica que comporta uma representação subjacente, um sistema de regras fonológicas ordenadas e uma representação superficial. No modelo gerativo, regras fonológicas são operações mentais que convertem representações fonológicas em fonéticas, seja por apagamento, inserção, união ou alteração de segmentos. Elas têm, portanto, papel crucial no modelo e são consideradas a expressão formal do conhecimento fonológico.

As regras intermedeiam dois níveis de representação: um subjacente e um superficial. Como evidência desses níveis de realidade psicológica, Carmen faz alusão a Hyman (1975), autor que apresenta argumentos para justificar a existência dos dois níveis, provenientes de dados de: i) intuição linguística; ii) sotaque estrangeiro; iii) lapsos de fala; iv) aquisição da linguagem.

Outra noção básica da fonologia gerativa discutida é a de traço, tanto como unidade constitutiva dos segmentos quanto como unidade mínima de análise. Os traços estão presentes tanto no nível fonológico, com função classificatória e distintiva, quanto no nível fonético, como escalas físicas contínuas. Capazes de apresentar alternâncias das línguas, os traços mostram que regras não se aplicam a conjuntos aleatórios de segmentos, mas a classes naturais. Além disso, estão universalmente disponíveis e fazem parte da Gramática Universal.

No entanto, apesar do alto poder explicativo da teoria, Carmen aponta algumas lacunas do modelo, como, por exemplo, a falta de hierarquização entre traços de um segmento. Na sequência, é enfatizado o surgimento das fonologias não lineares, modelos teóricos subsequentes dentro da perspectiva gerativa. A autora apresenta, então, uma análise na Fonologia Autossegmental. Nesse modelo, traços, dispostos hierarquicamente, são organizados em tiers e vinculados por linhas de associação. A nova formalização em estrutura arbórea impôs restrições à aplicação de regras e alterou sua formalização, sem abalar a concepção de existência de dois níveis de representação.

Para finalizar, Matzenauer destaca que aquilo que é codificado como parte da gramática é o que a experiência evidencia como fonologicamente pertinente. Esse, então, seria o conhecimento fonológico do falante.

A segunda fala fica a cargo de Luciani Tenani (UNESP - São José do Rio Preto), que aborda um dos modelos gerativos citados anteriormente: a Fonologia Prosódica. Tenani afirma que a Fonologia Prosódica estuda fenômenos de interface com outros componentes da gramática. A premissa do modelo é que a gramática dos sons em constituintes hierárquicos é regida por princípios universais, nem sempre em relação isomórfica com os constituintes morfossintáticos. Como exemplo, a conferencista menciona as sentenças Vi uma mesa redonda/Vi uma mesa-redonda, em que temos o mesmo número de unidades prosódicas, apesar de diferentes estruturas morfológicas. 


\section{REVISTA DA ABRALIN}

Ao admitir um mapeamento de constituintes baseado em relações (NESPOR; VOGEL, 1986), Tenani afirma que as evidências para a organização prosódica podem ser do tipo segmental, rítmico ou entoacional. O objeto escolhido para análise é o sintagma fonológico $(\phi)$.

Como evidência segmental, Tenani analisa casos de sândi vocálico - fenômeno de resolução de choque entre picos silábicos amplamente estudado no PB por Leda Bisol (BISOL, 1992, entre outros). Os casos de sândi englobam degeminação (alun[a]mericana), elisão (alun[o]landesa) ou ditongação (alu[wa]mericano). Para a ocorrência ou bloqueio do processo, estão em jogo tanto a tonicidade da segunda vogal, como também a configuração prosódica ${ }^{3}$. Ao investigar o fenômeno exaustivamente, Tenani conclui que a regra é bloqueada se a V2 carregar a proeminência de sintagma fonológico, como em aluna age.

A evidência rítmica mencionada baseia-se no choque acentual, que pode ser resolvido com o deslocamento de uma das unidades. Esse deslocamento acontece quando o primeiro acento estiver no nível da palavra e o segundo no do sintagma (Jòrnal Hóje, em referência ao nome do telejornal). Por outro lado, é bloqueado quando ambos forem do domínio do sintagma (jornál hóje, em referência a um jornal qualquer e um advérbio de tempo), já que alteraria o significado da frase.

Em relação à evidência entoacional, Tenani afirma que há uma relação complexa entre os eventos tonais e a preservação de informações da estrutura prosódica. Tenani mostra que a maior distância entre sílabas acentuadas gera tons complexos; se as sílabas são próximas, há maior variação nas configurações tonais. Esses resultados refletem a complexidade envolvendo a proximidade dos acentos dos sintagmas. As diferenças entre os tons impedem que certas sequências sejam percebidas como perturbadoras do ritmo.

No fim de sua fala, Tenani menciona que a Fonologia Prosódica prevê a organização prosódica a partir da sintaxe, sem se confundir com ela. A organização prosódica dos enunciados pode ser observada na fala, por meio de evidências como as apresentadas, mas também na escrita, a partir de grafias não convencionais.

A terceira conferencista, Christina Abreu Gomes (UFRJ), apresenta abordagens em direção oposta às demais: Fonologia baseada no Uso e Modelo de Exemplares. Como princípios gerais da proposta, Gomes destaca que i) o conhecimento linguístico é resultado da interação entre aspectos cognitivos inatos e experiência com a língua; ii) o uso impacta nas representações; iii) as generalizações emergem das formas; iv) não há separação entre léxico e gramática. Essa proposta toma a linguagem humana como um sistema adaptativo complexo.

A natureza das representações abrange informações fonéticas detalhadas da experiência de uso em diferentes situações sociais, interacionais e discursivas. As representações são dinâmicas e atualizadas em função da experiência com a língua. Os itens lexicais estão organizados em redes de relações baseadas em semelhanças no som e/ou no significado e se organizam em torno de uma representação dominante, mais frequente e relacionada à experiência do falante.

3 Segundo Tenani, a tonicidade da segunda vogal (V2) da sequência tem papel inibidor na aplicação do processo, o qual não acontece quando V2 é acentuada (ex. aluna árabe), mas se torna possível com a mudança da configuração prosódica, como em aluna árabemarroquina. 


\section{REVISTA DA ABRALIN}

Essas representações estariam organizadas em função de semelhança, frequência de uso e indexação social. Como evidência, a professora refere-se à síncope em proparoxítonas muito frequentes na língua (xí.c[a].ra > xi.cra), casos em que os falantes identificam, em geral, apenas duas sílabas (CONNINE et al., 2005).

Das representações, emergem abstrações, as quais são construídas gradualmente a partir do espaço fonético paramétrico e das representações das palavras no léxico - não há, portanto, separação entre fonética e fonologia. O processamento de uma palavra envolve o mapeamento do sinal acústico a uma categoria-alvo que corresponde à representação abstrata e a codificação do item junto da atualização do conjunto de exemplares.

Os efeitos de frequência capturam a influência do uso e de aspectos cognitivos. A frequência de ocorrência tem como consequência a robustez de uma forma armazenada; itens mais frequentes estão mais propensos a mudanças fonéticas, e menos propensos a mudanças analógicas. Já a frequência de tipo mostra o gerenciamento das abstrações. Categorias mais frequentes, como padrões silábicos ou morfemas específicos, podem ser atribuídos a novos itens ou empréstimos.

Como vantagens do modelo, Gomes elenca i) mesma modelagem para produção e percepção ou para idiossincrasias e generalizações; ii) abrangência de explicação; iii) superação do dualismo natureza vs. cultura.

Prestigiar essa mesa redonda é tarefa indispensável tanto para iniciantes como para pesquisadores avançados em Fonologia. Apesar do tom didático vislumbrado na fala das três professoras e destacado por muitos dos que assistiram à mesa ao vivo, mais do que um panorama geral, cada uma das participantes, referências da área, abordou com profundidade as diferentes teorias.

\section{REFERÊNCIAS}

BERKO, Jean; BROWN, Roger. Psycholinguistic Research Methods. In: MUSSEN, P. Handbook of research methods in child development. New York: John Wiley, 1960.

BISOL, Leda. Sândi vocálico externo: degeminação e elisão. Cadernos de Estudos Linguísticos, v. 23, p. 83-101, 1992.

BYBEE, Joan. Phonology and language use. Cambridge: Cambridge University Press. 2001.

CHOMSKY, Noam; HALLE, Morris. The sound pattern of English. New York: Harper \& Row. 1968.

CONNINE, Cynthia; RANBOM, Larissa; PATTERSON, David. On the representation of phonological variant frequency in spoken word recognition. Manuscrito, 2005.

FONOLOGIA. Mesa redonda apresentada por Carmen Matzenauer, Luciani Tenani e Christina Abreu Gomes, sob moderação de José Magalhães [s.l., s.n], 2020. 1 vídeo (2h 50min 50s). Publicado pelo canal da Associação Brasileira de Linguística. Disponível em: https://www.youtube.com/watch?v=G4cPkxK8lqU\&t=8794s. Acesso em: 29 jul. 2020.

HYMAN, Larry. Phonology: theory and analysis. New York: Holt, Rinehart \& Winston, 1975. 


\section{REVISTA DA ABRALIN}

KIPARSKY, Paul. From Cyclic Phonology to Lexical Phonology. In: VAN DER HULST, Harry; SMITH, Norval (eds.) The structure of phonological representations. Vol 1. Dordrecht: Foris, 131-175. 1982.

LIBERMAN, Mark; PRINCE, Alan. On stress and linguistic rhythm. Linguistic inquiry, Cambridge, n.8, p.249-336, 1977.

MIRANDA, Ana Ruth Moresco. Reflexões sobre a fonologia e a aquisição da linguagem oral e escrita, Veredas (UFJF), online, v.16, p.118-135, 2012

NESPOR, Marina; VOGEL, Irene. Prosodic Phonology. Dordrecht: Foris Publications. 1986.

PEREIRA, Isabel. Panorama das abordagens lingüísticas das questões prosódicas. In: PEREIRA, Isabel et al. Estudos em Prosódia. Lisboa: Edições Colibri, 1992, p. 1-32.

PRINCE, Alan; SMOLENSKY, Paul. Optimality Theory: Constraint interaction in generative grammar, Rutgers Center for Cognitive Science Technical Report TR-2. 1993.

SELKIRK, Elisabeth. Phonology and syntax: the relation between sound and structure. Cambridge, MA: The MIT Press, 1984. 